\title{
Neoadjuvant Pertuzumab plus Trastuzumab in Combination with Docetaxel and Carboplatin in Patients with HER2 Positive Breast Cancer: Real-World Data from a National Institute of Oncology in Poland.
}

Agnieszka Jagiello-Gruszfeld (1), Magdalena Rosinska (2), Małgorzata Meluch (1), Katarzyna Pogoda (1), Anna Niwinska (1), Renata Sienkiewicz (1), Aleksander Grous (1), Paweł Winter (1), Zbigniew Nowecki (1)

1. Breast Cancer and Reconstructive Surgery Department, Maria Sklodowska-Curie National Research Institute of Oncology, Warsaw, Poland

2. Department of Oncological Mathematics, Maria Sklodowska-Curie National Research Institute of Oncology, Warsaw, Poland

\section{Address for correspondence:}

Agnieszka Jagiello-Gruszfeld

Breast Cancer and Reconstructive Surgery Department, Maria Sklodowska-Curie National Research Institute of Oncology

ul. Roentgena 5, 02-781 Warszawa

e-mail: agnieszka.jagiellogruszfeld@gmail.com

\begin{abstract}
Neoadjuvant systemic therapy has now become the the standard in early breast cancer management. Chemotherapy in combination with trastuzumab +/- pertuzumab targeted therapy can improve rates of pathologic complete response (pCR) in patients with HER2-positive breast cancer. Achieving a pCR is considered a good prognostic factor, in particular in patients with more aggressive breast cancer subtypes such as TNBC or HER2 positive cancers. Furthermore, most studies demonstrate that chemotherapy in combination with trastuzumab and pertuzumab is well tolerated. The retrospective analysis presented here concentrates on neoadjuvant therapy with the TCbH-P regimen, with a particular emphasis on patients over 60 years of age. We analysed the factors affecting the achievement of $\mathrm{pCR}$ and presented adverse effects of the applied therapies, which opened a discussion about optimizing the therapy of older patients with HER-2 positive breast cancer.
\end{abstract}

Keywords: Breast cancer; neoadjuvant chemotherapy; elderly; HER2, pathological complete response; safety

\section{Introduction}

Neoadjuvant therapy is now the standard of care for most patients diagnosed with early HER2positive breast cancer [1-3]. It is believed that in the case of patients with a higher risk of recurrence, especially with confirmed axillary lymph node involvement and lack of hormone receptors, the so-called dual anti-HER2 blockade with pertuzumab and trastuzumab in combination with chemotherapy is more effective than trastuzumab with chemotherapy [1-3]. The combination of pertuzumab, trastuzumab and docetaxel improved $\mathrm{pCR}$ rates compared to 
trastuzumab and docetaxel therapies from $21 \%$ to $39 \%$ [4,5]. In terms of survival, higher pCR rates are correlated with longer survival rates in this population $[6,7]$.

Anthracyclines may be used sequentially, followed by taxanes in combination with anti-HER2 drugs or an anthracycline-free regimen containing taxanes and carboplatin with targeted therapy is recommended [1-3]. The results of studies confirm similar efficacy of both treatment modalities, with a lower risk of cardiotoxicity in the case of anthracycline-free regimens [8-11].

Response to neoadjuvant treatment is a source of important information about tumor biology and is one of well evaluated prognostic factors. [7, 12]. Based on the evaluation of the surgical specimens for pathologic complete response (pCR), decisions are made to continue the current therapy (trastuzumab +/- pertuzumab) following the surgery or, if the minimal residual disease is found, to switch to trastuzumab-emtansine to optimize long-term outcomes [13-15].

In recent years, the question of providing optimal treatment options for older women with breast cancer has been discussed ever more frequently. Available data on breast cancer rates in the U.S. demonstrate that most patients newly diagnosed with breast cancer are below the age of 65 (58\%), whereas most breast cancer deaths occur in women aged $\geq 65$ years $(60 \%)$ [16].

In Poland, 18,869 women were diagnosed with breast cancer in 2018, of which 10,523 (66\%) were below the age of 65 . In the same year, there were 6,895 deaths from breast cancer, of which 4,609 (67\%) were in women aged 65 and older [17].

Although many publications demonstrate that older women with no co-existing medical conditions tolerate toxic treatment regimens (such as TCbH-P or TCH) well, the percentage of older patients in randomized trials is small $[18,19]$. In fact, most authors emphasize that older women face an increased risk of severe treatment-induced toxicities, in particular of left ventricular systolic dysfunction (LVSD) [20,21]. Studies show that nearly 4\% of patients develop congestive heart failure (CHF) during trastuzumab therapy. In patients aged over 60 years, this risk is increased up to $5.4 \%$ [22].

\section{Aim}

The primary objective of this study was a retrospective evaluation of the efficacy and safety of $\mathrm{TCbH}-\mathrm{P}$ regimen (docetaxel, carboplatin, trastuzumab, and pertuzumab) in patients eligible for treatment with this neoadjuvant regimen in the Breast Cancer and Reconstructive Surgery Department. In addition, the data obtained were analysed to account for the age of the patients ( $<60$ years old vs $\geq 60$ years old). The age limit was set at 60 years, as a similar age limit is usually set when patients are eligible for dose-neoadjuvant chemotherapy $[2,3]$.

\section{Ethics Statement}

The study protocol was approved by the Ethics Committee of Maria Sklodowska-Curie National Research Institute of Oncology (No 12/2021). The study was performed per Good Clinical Practice standards and the ethical principles that have their origin in the Declaration of Helsinki. All patients provided informed consent for use of their data for research purposes.

\section{Materials and Methods}

We analysed medical records of breast cancer patients who primary treated with neoadjuvant therapy with the TCbH-P regimen from 20/01/2018 to 10/12/2018 and then underwent radical surgery $+/$ - radiotherapy. 
All patients met the following criteria: ECOG 0-1 performance status, histopathological diagnosis of HER2-positive invasive breast cancer, breast cancer staging (cT1-4, cN0-3, M0), neoadjuvant therapy with a TCbH-P regimen, and baseline left ventricular ejection fraction (LVEF) of $\geq 50 \%$.

Initially, a core needle biopsy was used to diagnose a breast tumour. Suspicious axillary lymph nodes were evaluated using a ultrasound (US) -guided fine needle biopsy. The presence of estrogen receptor (ER) and progesterone receptor (PR) was identified when $\geq 1 \%$ of nuclei stained positive; if $<1 \%$ of nuclei stained positive, it was considered a negative result. The HER2 status was considered positive based on an immunohistochemistry score of $3+$ or $2+$, which was confirmed with a positive FISH test [1].

All patients received the TCbH-P regimen (docetaxel, carboplatin, trastuzumab, and pertuzumab) at the following doses: docetaxel $75 \mathrm{mg} / \mathrm{m} 2$, carboplatin (AUC $6 \mathrm{mg} / \mathrm{mL} / \mathrm{min}$ ) intravenously, once every 3 weeks, trastuzumab: loading dose $8 \mathrm{mg} / \mathrm{kg}$ followed by $6 \mathrm{mg} / \mathrm{kg}$ intravenously, once every 3 weeks, pertuzumab: loading dose $840 \mathrm{mg}$ followed by $420 \mathrm{mg}$ intravenously, once every 3 weeks.

All patients underwent surgery after 6 cycles of neoadjuvant therapy. The response to treatment was assessed using the residual cancer burden (RCB) calculator ( http://www3.mdanderson.org/app/medcalc/index.cfm?pagename=jsconvert3).Since T-DM1 (trastuzumab emtansine) is not currently reimbursed in Poland, trastuzumab (without pertuzumab, which is not reimbursed in Poland for adjuvant therapy, either) was continued postoperatively for up to 18 cycles, whether the pCR was achieved or the minimal residual disease remained present, the pCR was achieved or the minimal residual disease remained present.

All patients with positive hormone receptors also received hormone therapy after the surgery, as per the current guidelines, for at least 5 years.

Prior to the neoadjuvant therapy, the patients underwent mammography and were given breast and regional lymph nodes US, abdominal US or computed tomography (CT), chest X-ray or CT, bone scintigraphy, ECG, echocardiography, and blood tests.

All patients received peg-GCSF after each course of chemotherapy routinely.

Adverse events were assessed according to the Common Terminology Criteria for Adverse Events, version 4.0 [23]. Echocardiography was used to monitor left ventricular ejection fraction (LVEF); it was performed before the start of treatment and then every 12 weeks during the neoadjuvant therapy and every 3 months during adjuvant therapy.

All patients were evaluated for response every 6 weeks using breast and lymph node US.

\section{Statistical Analysis}

Descriptive statistics were used to describe the characteristics of the study group: mean, median, first and third quartile (IQR) values and range. The normality of the distribution of the individual parameters evaluated in the study was verified using the Shapiro-Wilk test. In the case of normal distribution, Student's t distribution test was used to compare mean values of independent variables. For the other parameters without normal distributions, appropriate 
methods of statistical analysis were selected based on non-parametric tests. The MannWhitney $U$ test was used to compare numerical variables between the two groups observed. Spearman's rank correlation coefficient (monotonic relationships, linear or not) and Pearson correlation coefficient (linear monotonic relationships) were used to examine the existence of monotonic relationships between two variables. All calculations and graphs were performed using the R stats package, version 4.0.2.

\section{Results}

Thirty-four patients meeting the eligibility criteria were included in the study. Patient demographics are described in Table 1.

The median age of the group was 46 (30-68) years old, of which 58.8\% were patients diagnosed with luminal B, HER2 positive cancer. Only 7 patients were $\geq 60$ years $(20.6 \%)$; that was due to the caution in qualifying older patients for a rather toxic treatment regimen as there were a small number of research reports regarding the safety of treatment in this group of patients.

Before they were started on chemotherapy, all patients had a normal LVEF $>50 \%$.

Clinically, the size of the breast tumour during the therapy decreased, which was evaluated clinically and by US.

$58.8 \%$ of patients underwent mastectomy ( + immediate breast reconstruction in 8 patients) and $38.3 \%$ underwent wide local tumour excision ; 1 patient $(2.9 \%)$ did not undergo breast surgery as there was no tumour in the breast (T0). 53\% of patients underwent axillary lymphadenectomy, while $47.1 \%$ of patients had a sentinel node (SN) procedure (in $8.9 \%$ patients targeted axillary dissection was performed) .

The most common severe complications (grade 3 or 4) were neutropenia and febrile neutropenia. Among patients aged $\geq 60$ years, the most common adverse reactions grade $3 / 4$ were diarrhoea (28\%), neutropenia (28\%), and febrile neutropenia (28\%).

Treatment toxicities are shown in Table 2.

Ten patients $(29.4 \%)$ had the doses of carboplatin reduced, and four patients $(11.7 \%)$ had the doses of docetaxel reduced

Sixteen patients received ESA supportive therapy (at least 1 dose of darbepoetin) during chemotherapy. Two patients required a transfusion of red blood cells due to grade $3 / 4$ anaemia.

All patients completed the expected 6 cycles of treatment and underwent surgery.

None of the patients had a decrease in LVEF or clinical manifestations of heart failure during all period of systemic therapy. No complications-related mortality was observed.

Pathologic complete response was observed in 18 (52.9\%) patients.). The average time from the disease diagnosis to the last follow-up was $27.15(+/-5.53)$ months. During this time, relapse was observed in 1 patient $(2.9 \%)$.

The characteristics of the responses obtained are shown in Table 3.

A statistically significant relationship was identified between the type of response achieved ( $\mathrm{pCR}$ vs non-pCR) and the presence of ER $(\mathrm{p}<0.05)$. In a univariate analysis, the odds of 
achieving pCR were 14 times higher in the ER-negative arm compared to the ER-positive group $(p=0.004)$. This was confirmed by the multivariate analysis: ER status (OR: $0.01,95 \%$ CI: 0.00 $-0.16 ; p=0.005)$.

No correlation was identified between the occurrence of $\mathrm{pCR}$ and the primary stage of the disease.

The results describing the response to treatment depending on age, disease staging, and ER and PR status are shown in Table 4.

It was observed that in the group of patients with non-luminal, HER2-positive cancers, the pCR rate did not depend on age of patients compared to patients with luminal HER2-positive cancer where mainly young patients achieved pCR (Figure 1.). As such, the use of aggressive chemotherapy in combination with dual anti-HER2 blockade (pertuzumab + trastuzumab) in patients over 60 years old diagnosed with luminal HER2-positive cancer might not be necessary due to the small chance of achieving the expected pCR. The use of trastuzumab with weekly paclitaxel is probably a sufficient method of treatment in this group of patients. However, it must be emphasized that this hypothesis cannot be definitively proven due to a small number of subjects.

\section{Discussion}

The diagnosis of breast cancer with high HER2 expression levels is associated with a worse prognosis and the disease progressing more dynamically. Significant improvements in therapy outcomes for this biologic subtype were achieved when HER2 blockers were introduced into routine management $[24,25]$.

Improved long-term outcomes were also achieved when neoadjuvant treatment with anti-HER2 therapy was included in the standard of care [4-9]. The use of neoadjuvant therapy can facilitate surgical treatment, increase the number of patients eligible for breast-conserving therapy (BCT), determine the degree of sensitivity to the therapy used and identify patients who do not achieve $\mathrm{pCR}$ and should be treated more intensively after the surgery [1-3, 13]. It is currently recommended that patients with HER2-positive cancers at high risk of recurrence or HER2positive locally advanced cancers should be treated with a combination of chemotherapy and dual anti-HER blockade, i.e. trastuzumab and pertuzumab $[4,5,26]$. The most effective regimens for neoadjuvant treatment are considered to be an anthracycline-free chemotherapy regimen i.e. TCbH-P and anthracyclines-containing sequential regimens AC-THP. It should be emphasized that anthracycline-containing regimens are associated with a higher risk of cardiotoxicity $[8,27]$.

The TRYPHAENA and TRAIN-2 studies did not demonstrate a significant difference in pCR rates between regimens with or without anthracyclines [8,27], with pCR rates exceeding $65 \%$ in patients receiving anthracyclines-free regimens. In this context, the TCbH-P regimen seems to be a more rational option for neoadjuvant therapy, in particular since most women undergoing the treatment are likely to survive for many years without cancer recurrence [2831].

Several clinical trials have evaluated the efficacy and safety of TCbH-P regimen as perioperative treatment $[5,8,11]$. In most publications, the percentage of pCR was $55-66 \%$ [8, $9,27]$, whereas in our study we identified pCR in only $52.9 \%$ of women. We believe this is due 
to the high proportion of HER2-positive luminal cancer patients, with pCR found in only $33.3 \%$ of them (vs 66.7\% in ER-negative, HER2-positive patients), and the significantly lower chance of pCR observed in our patients aged 60 years and older, compared to younger patients $(11.1 \%$ vs $89.9 \%$ ).

In observational studies describing the everyday clinical practice, patients with no significant co-existing medical conditions and being younger are often selected for treatment with dualblockade anti-HER2 regimens, in particular TCbH-P [32, 33]. The results of our study support the validity of such choices since, in particular for the group of ER-positive patients, the benefit of using a relatively toxic TCbH-P regimen is unlikely to carry any extra benefits and may lead to serious complications.

The most common adverse events found in our study were anaemia, weakness, neuropathy, and neutropenia. Diarrhoea was observed in our patients less frequently $(26 \%)$ than in other studies, whereas most publications report the occurrence of diarrhoea in $40-56 \%$ of patients started on the treatment $[8,9,27,32,33]$. It should be noted, then, that we observed diarrhoea significantly more often in patients aged 60 years and older $(71 \%)$ than in younger patients.

We reported thrombocytopenia slightly less frequently than in other studies (38\% of patients only), with no patient having grade 4 thrombocytopenia, which is probably related to the relatively high number of patients that received a reduced dose of carboplatin $(29.4 \%)$. The reason for the dose reduction was mainly neuropathy, neutropenia and anaemia.

We did not observe symptomatic heart failure or a significant decrease in LVEF (less than 10\% compared with baseline) in any of assessed patients.

The disadvantages of our study are the small number of subjects and the relatively short followup time (slightly more than 2 years); nevertheless, it is a group treated in one centre with the same eligibility criteria and supportive treatment applied during the therapy.

\section{Conclusions}

Our study has confirmed that the TCbH-P regimen is safe and relatively effective in the neoadjuvant treatment of patients with HER2-positive breast cancer. No case of myocardial dysfunction or significant decrease in LVEF was observed. However, our results suggest that consideration should be given to whether the TCbH-p regimen is the optimal choice for luminal B, HER2-positive cancer patients over the age of 60 , as in this group the chance of achieving pCR is low, while there is a risk of serious treatment toxicities.

\section{Source of funding}

This work received no funding

\section{References:}

1. Cardoso F, Kyriakides S, Ohno S, Penault-Llorca F, Poortmans P, Rubio IT, et al. Early breast cancer: ESMO Clinical Practice Guidelines for diagnosis, treatment and follow-up. Ann Oncol 2019;30(8):1194-220.

2. AGO (German Gynecological Oncology Group). AGO Breast Cancer guidelines v1.2021. 
3. National Comprehensive Cancer Network (NCCN). NCCN Clinical Practice Guidelines in Oncology (NCCN Guidelines ${ }^{\circledR}$ ): Breast Cancer. Version 1. 2021.

4. L. Gianni, T. Pienkowski, Y.-.H. Im, L. Roman, L-M Tseng, M.-.C. Liu, et al., Efficacy and safety of neoadjuvant pertuzumab and trastuzumab in women with locally advanced, inflammatory, or early HER2-positive breast cancer (NeoSphere)-A randomized multicenter, open-label, phase 2 trial, Lancet Oncol. 13 (1) (2012 Jan 1) 25-32.

5. L. Gianni, T. Pienkowski, Y.-H. Im et al., 5-year analysis of neoadjuvant pertuzumab and trastuzumab in patients with locally advanced, inflammatory, or early-stage HER2-positive breast cancer (NeoSphere): a multicentre, open-label, phase 2 randomised trial, The Lancet Oncology, vol. 17, no. 6, pp. 791-800, 2016.

6. Y. Yamashita, Y. Tanaka, S. Kono et al., Effectiveness of Pertuzumab, Trastuzumab, and Docetaxel Combination Neoadjuvant Chemotherapy for HER2-Positive Inflammatory Breast Cancer: A Case Report, Breast Care, vol. 12, no. 1, pp. 45-47, 2017.

7. P. Cortazar, L. Zhang, M. Untch, K. Mehta, J.P. Costantino, N. Wolmark, et al., Pathological complete response and long-term clinical benefit in breast cancer - The CTNeoBC pooled analysis, Lancet 384 (9938) (2014 Jul 12) 164-172.

8. A. Schneeweiss, S. Chia, T. Hickish, V. Harvey, A. Eniu, R. Hegg, et al., Pertuzumab plus trastuzumab in combination with standard neoadjuvant anthracycline containing and anthracycline-free chemotherapy regimens in patients with HER2-positive early breast cancerA randomized phase II cardiac safety study (TRYPHAENA), Ann. Oncol. 24 (9) (2013 Sep 1) $2278-2284$.

9. S. Gonzalez-Santiago, C. Saura, E. Ciruelos, J.L. Alonso, P. de la Morena, M. Santisteban Eslava, et al., Real-world effectiveness of dual HER2 blockade with pertuzumab and trastuzumab for neoadjuvant treatment of HER2-positive early breast cancer (The NEOPETRA Study), Breast Cancer Res. Treat. 184 (2) (2020 Nov 1) 469-479.

10. T. Berg, M.-.B. Jensen, E.H. Jakobsen, S. Al-Rawi, J. Kenholm, M. Andersson, Neoadjuvant chemotherapy and HER2 dual blockade including biosimilar trastuzumab (SB3) for HER2-positive early breast cancer-Population-based real-world data from the Danish Breast Cancer Group (DBCG), Breast 54 (2020 Dec 1) 242-247.

11. S.R. Tiwari, B. Calhoun, J. Abraham, G.T. Budd, H.C.F. Moore, A. Fanning, et al., Efficacy and safety of neoadjuvant docetaxel, carboplatin, trastuzumab/pertuzumab [TCH-P] in non-metastatic HER2+ breast cancer-The Cleveland Clinic experience, J. Clin. Oncol. 33 (15_suppl) (2015 May 20) 531.

12. A. Katayama, I.M. Miligy, S. Shiino, M.S. Toss, K. Eldib, S. Kurozumi, et al., Predictors of pathological complete response to neoadjuvant treatment and changes to post-neoadjuvant HER2 status in HER2-positive invasive breast cancer, Mod. Pathol. 34 (2021) 1271-1281, https://doi.org/10.1038/s41379-021-00738- 5.

13. G. von Minckwitz, C.-.S. Huang, M.S. Mano, S. Loibl, E.P. Mamounas, M. Untch, et al., Trastuzumab emtansine for residual invasive HER2-positive breast cancer, N. Engl. J. Med. 380 (7) (2019 Feb 14) 617-628. 
14. Jackisch C, Cortazar P, Geyer CE Jr, Gianni L, Gligorov J, Machackova Z, Perez EA, Schneeweiss A, Tolaney SM, Untch M, Wardley A, Piccart M. Risk-based decision-making in the treatment of HER2-positive early breast cancer: Recommendations based on the current state of knowledge. Cancer Treat Rev. 2021 Sep;99:102229. doi: 10.1016/j.ctrv.2021.102229. Epub 2021 May 20. PMID: 34139476.

15. Yau C, Osdoit M, van der Noordaa M, Shad S, Wei J, de Croze D, Hamy AS, Laé M, Reyal F, Sonke GS, Steenbruggen TG, van Seijen M, Wesseling J, Martín M, Del Monte-Millán M, López-Tarruella S; I-SPY 2 Trial Consortium, Boughey JC, Goetz MP, Hoskin T, Gould R, Valero V, Edge SB, Abraham JE, Bartlett JMS, Caldas C, Dunn J, Earl H, Hayward L, Hiller L, Provenzano E, Sammut SJ, Thomas JS, Cameron D, Graham A, Hall P, Mackintosh L, Fan F, Godwin AK, Schwensen K, Sharma P, DeMichele AM, Cole K, Pusztai L, Kim MO, van 't Veer LJ, Esserman LJ, Symmans WF. Residual cancer burden after neoadjuvant chemotherapy and long-term survival outcomes in breast cancer: a multicentre pooled analysis of 5161 patients. Lancet Oncol. 2021 Dec 10:S1470-2045(21)00589-1. doi: 10.1016/S14702045(21)00589-1. Epub ahead of print. PMID: 34902335.

16. B. D. Smith, J. Jiang, S. S. McLaughlin et al., Improvement in breast cancer outcomes over time: are older women missing out?" Journal of Clinical Oncology, vol. 29, no. 35, pp. 4647-4653, 2011.

17. Wojciechowska Urszula, Didkowska Joanna. Zachorowania i zgony na nowotwory złośliwe w Polsce. Krajowy Rejestr Nowotworów, Narodowy Instytut Onkologii im. Marii Skłodowskiej-Curie - Państwowy Instytut Badawczy. Available on: http://onkologia.org.pl/raporty/ dostęp z dnia 26/12/2021.

18. C. Owusu, T. L. Lash, and R. A. Silliman, Effect of undertreatment on the disparity in age-related breast cancer-specific survival among older women, Breast Cancer Research and Treatment, vol. 102, no. 2, pp. 227-236, 2007.

19. G. R. Williams, E. Jones, and H. B. Muss, Challenges in the Treatment of Older Breast Cancer Patients, Hematology/Oncology Clinics of North America, vol. 27, no. 4, pp. 785-804, 2013.

20. G.M.Cote, D. B. Sawyer, and B. A. Chabner, ERBB2 inhibition and heart failure, The New England Journal of Medicine, vol. 367, no. 22, pp. 2150-2153, 2012.

21. C. Dang, H. Guo, J. Najita et al., Cardiac outcomes of patients receiving adjuvant weekly paclitaxel and trastuzumab for node negative, ERBB2-positive breast cancer, JAMA Oncology, vol. 2, no. 1, pp. 29-36, 2016.

22. S. M. Swain, M. S. Ewer, J. Cortés et al., Cardiac tolerability of pertuzumab plus trastuzumab plus docetaxel in patients with HER2-positive metastatic breast cancer in CLEOPATRA: A randomized, double-blind, placebo-controlled phase III study, The Oncologist, vol. 18, no. 3, pp. 257-264, 2013.

23. https://ctep.cancer.gov/protocoldevelopment/electronic_applications/ctc.htm\#ctc_50

24. Slamon D, Eiermann W, Robert N, et al. Adjuvant Trastuzumab in HER2-positive Breast Cancer. N Engl J Med 2011;365:1273-83. 
25. Swain SM, Miles D, Kim SB, et al. Pertuzumab, trastuzumab, and docetaxel for HER2positive metastatic breast cancer (CLEOPATRA): end-of-study results from a double-blind, randomised, placebo-controlled, phase 3 study. Lancet Oncol 2020;21:519-30.

26. Shao Z, Pang D, Yang H, et al. Efficacy, Safety, and Tolerability of Pertuzumab, Trastuzumab, and Docetaxel for Patients With Early or Locally Advanced ERBB2- Positive Breast Cancer in Asia: The PEONY Phase 3 Randomized Clinical Trial. JAMA Oncol 2020;6:e193692.

27. van Ramshorst MS, van der Voort A, van Werkhoven ED, et al. Neoadjuvant chemotherapy with or without anthracyclines in the presence of dual HER2 blockade for HER2positive breast cancer (TRAIN-2): a multicentre, open-label, randomised, phase 3 trial. Lancet Oncol 2018;19:1630-40.

28. Siegel R, DeSantis C, Virgo K et al. Cancer treatment and survivorship statistics, 2012. CA Cancer J Clin, 2012; 62: 220-241.

29. Armstrong GT, Oeffinger KC, Chen Y et al. Modifiable risk factors and major cardiac events among adult survivors of childhood cancer. J Clin Oncol, 2013; 31: 3673-3680.

30. von Minckwitz G, Procter M, de Azambuja E, et al. Adjuvant pertuzumab and trastuzumab in early HER2- positive breast cancer. N Engl J Med 2017;377:122-31.

31. Mantarro S, Rossi M, Bonifazi M, et al. Risk of severe cardiotoxicity following treatment with trastuzumab: a meta-analysis of randomized and cohort studies of 29,000 women with breast cancer. Intern Emerg Med 2016;11:123-40.

32. Lv M, Guo H, Wang C, Tian P, Ma Y, Chen X, Luo S. Neoadjuvant docetaxel with or without carboplatin plus dual HER2 blockade for HER2-positive breast cancer: a retrospective multi-centre Chinese study. Gland Surg. 2020 Dec;9(6):2079-2090. doi: 10.21037/gs-20-791. PMID: 33447559; PMCID: PMC7804556.

33. Arora S, Gogia DA, Deo S, Sharma D, Mathur SR. Neoadjuvant pertuzumab plus trastuzumab in combination with anthracycline- free chemotherapy regimen in patients with HER2 positive breast cancer-Real-world data from a single centre in India. Cancer Treat Res Commun. 2021;29:100483. doi: 10.1016/j.ctarc.2021.100483. Epub 2021 Oct 21. PMID: 34710849 .

Table 1. Patient characteristic.

\begin{tabular}{|l|l|l|l|}
\hline Variable & Parameter & $\mathrm{N}=34$ & $\%$ \\
\hline $\begin{array}{l}\text { Age at diagnosis of } \\
\text { breast cancer [years] }\end{array}$ & Median (IQR) & $46(39.25-54.25)$ & \\
\cline { 2 - 4 } & Range & $30-68$ & \\
\hline $\begin{array}{l}\text { Age at diagnosis of } \\
\text { breast cancer [years] } \\
\text { breakdown }\end{array}$ & $<60$ years old & 27 & $79.4 \%$ \\
\cline { 2 - 4 } & $\geq 60$ years old & 7 & $20.6 \%$ \\
\hline \multirow{2}{*}{ cT } & 0 & 1 & $2.9 \%$ \\
\cline { 2 - 4 } & 1 & 3 & $8.8 \%$ \\
\cline { 2 - 4 } & 2 & 21 & $61.8 \%$ \\
\hline
\end{tabular}




\begin{tabular}{|c|c|c|c|}
\hline & 3 & 6 & $17.6 \%$ \\
\hline & $4 \mathrm{~d}$ & 3 & $8.8 \%$ \\
\hline \multirow[t]{4}{*}{$\mathrm{cN}$} & 0 & 13 & $38.2 \%$ \\
\hline & 1 & 14 & $41.2 \%$ \\
\hline & 2 & 5 & $14.7 \%$ \\
\hline & 3 & 2 & $5.9 \%$ \\
\hline \multirow[t]{2}{*}{ ER } & positive & 20 & $58.8 \%$ \\
\hline & negative & 14 & $41.2 \%$ \\
\hline \multirow[t]{2}{*}{ PR } & positive & 15 & $44.1 \%$ \\
\hline & negative & 19 & $55.9 \%$ \\
\hline \multirow{4}{*}{$\begin{array}{l}\text { Type of treatment - } \\
\text { breast }\end{array}$} & Mastectomy & 12 & $35.3 \%$ \\
\hline & $\begin{array}{l}\text { Mastectomy }+ \\
\text { immediate breast } \\
\text { reconstruction }\end{array}$ & 8 & $23.5 \%$ \\
\hline & $\begin{array}{l}\text { Breast conserving } \\
\text { surgery (BCS) }\end{array}$ & 13 & $38.3 \%$ \\
\hline & $\begin{array}{l}\text { No treatment (T0 } \\
\text { patient) }\end{array}$ & 1 & $2.9 \%$ \\
\hline \multirow{3}{*}{$\begin{array}{l}\text { Type of treatment - } \\
\text { axilla }\end{array}$} & Axillary dissection & 18 & $53 \%$ \\
\hline & Sentinental node $(\mathrm{SN})$ & 13 & $38.2 \%$ \\
\hline & $\begin{array}{l}\text { Targeted axillary } \\
\text { dissection (TAD) }\end{array}$ & 3 & $8.9 \%$ \\
\hline
\end{tabular}

Table 2. Treatment toxicity.

\begin{tabular}{|c|c|c|c|c|c|c|}
\hline \multirow[t]{2}{*}{ Toxicity } & \multicolumn{3}{|c|}{ Incidence (any grade) } & \multicolumn{3}{|c|}{ Grade 3 or 4} \\
\hline & Any & $\begin{array}{l}\text { Patients } \\
<60\end{array}$ & $\begin{array}{l}\text { Patients } \\
\geq 60\end{array}$ & Any & $\begin{array}{l}\text { Patients } \\
<60\end{array}$ & $\begin{array}{l}\text { Patients } \\
\geq 60\end{array}$ \\
\hline Diarrhoea & $9(26 \%)$ & $4(15 \%)$ & $5(71 \%)$ & $2(6 \%)$ & 0 & $2(28 \%)$ \\
\hline Thrombocytopenia & $13(38 \%)$ & $9(33 \%)$ & $4(57 \%)$ & 0 & 0 & 0 \\
\hline Neutropenia & $14(41 \%)$ & $\begin{array}{l}10 \\
(37 \%)\end{array}$ & $4(57 \%)$ & $4(12 \%)$ & $2(7 \%)$ & $2(28 \%)$ \\
\hline $\begin{array}{l}\text { Febrile } \\
\text { neutropenia }\end{array}$ & $4(12 \%)$ & $2(7 \%)$ & $2(28 \%)$ & $4(12 \%)$ & $2(7 \%)$ & $2(28 \%)$ \\
\hline Anaemia & $27(79 \%)$ & $\begin{array}{l}23 \\
(85 \%)\end{array}$ & $4(57 \%)$ & $2(6 \%)$ & $1(3.5 \%)$ & $1(14 \%)$ \\
\hline Fatigue & $24(70 \%)$ & $\begin{array}{l}19 \\
(70 \%)\end{array}$ & $5(71 \%)$ & $2(6 \%)$ & $1(3.5 \%)$ & $1(14 \%)$ \\
\hline Neuropathy & $22(65 \%)$ & $\begin{array}{l}17 \\
(63 \%)\end{array}$ & $5(71 \%)$ & 0 & 0 & 0 \\
\hline Mucositis & $3(9 \%)$ & $2(7 \%)$ & $1(14 \%)$ & 0 & 0 & 0 \\
\hline $\begin{array}{l}\text { Cardiac } \\
\text { dysfunction }\end{array}$ & 0 & 0 & 0 & 0 & 0 & 0 \\
\hline
\end{tabular}


Table 3. Characteristics of achieved responses to treatment.

\begin{tabular}{|l|l|l|}
\hline Characteristic & Parameter & $\mathbf{\%}(\mathbf{N}=\mathbf{3 4})$ \\
\hline Achieved response to neoadjuvant treatment & pCR & $52.9 \%(\mathrm{~N}=18)$ \\
\cline { 2 - 3 } & non pCR & $47.1 \%(\mathrm{~N}=16)$ \\
\hline \multirow{2}{*}{ Residual cancer burden (RCB) - only patients with non-pCR } & I & $20.6 \%(\mathrm{~N}=7)$ \\
\cline { 2 - 3 } & II & $12 \%(\mathrm{~N}=4)$ \\
\cline { 2 - 3 } & III & $15 \%(\mathrm{~N}=5)$ \\
\hline
\end{tabular}

Table 4. Response to treatment depending on age, disease stage, and ER and PR status.

\begin{tabular}{|c|c|c|c|c|}
\hline Variable & Parameter & $\operatorname{pCR}(\mathrm{N}=18)$ & $\begin{array}{l}\text { Non-pCR } \\
(\mathrm{N}=16)\end{array}$ & p-value \\
\hline \multirow{3}{*}{$\begin{array}{l}\text { Age at diagnosis of } \\
\text { breast cancer [years] }\end{array}$} & $\mathrm{N}$ & 18 & 16 & \multirow[t]{3}{*}{0.07512} \\
\hline & Median & 43 & 50 & \\
\hline & Range & $30-67$ & $33-68$ & \\
\hline \multirow{2}{*}{$\begin{array}{l}\text { Age at diagnosis of } \\
\text { breast cancer [years] - } \\
\text { breakdown }\end{array}$} & $\begin{array}{l}<60 \text { years } \\
\text { old }\end{array}$ & $88.9 \%(\mathrm{~N}=16)$ & $68.8 \%(\mathrm{~N}=11)$ & \multirow[t]{2}{*}{0.2143} \\
\hline & $\begin{array}{l}\geq 60 \text { years } \\
\text { old }\end{array}$ & $11.1 \%(\mathrm{~N}=2)$ & $31.2 \%(\mathrm{~N}=5)$ & \\
\hline \multirow[t]{5}{*}{ cT } & 0 & $5.6 \%(\mathrm{~N}=1)$ & $0 \%(\mathrm{~N}=0)$ & \multirow[t]{5}{*}{0.8128} \\
\hline & 1 & $11.1 \%(\mathrm{~N}=2)$ & $6.2 \%(\mathrm{~N}=1)$ & \\
\hline & 2 & $61.1 \%(\mathrm{~N}=11)$ & $62.5 \%(\mathrm{~N}=10)$ & \\
\hline & 3 & $11.1 \%(\mathrm{~N}=2)$ & $25 \%(\mathrm{~N}=4)$ & \\
\hline & $4 d$ & $11.1 \%(\mathrm{~N}=2)$ & $6.2 \%(\mathrm{~N}=1)$ & \\
\hline \multirow[t]{4}{*}{$\mathrm{cN}$} & 0 & $38.9 \%(\mathrm{~N}=7)$ & $37.5 \%(\mathrm{~N}=6)$ & \multirow[t]{4}{*}{1} \\
\hline & 1 & $38.9 \%(\mathrm{~N}=7)$ & $43.8 \%(\mathrm{~N}=7)$ & \\
\hline & 2 & $16.7 \%(\mathrm{~N}=3)$ & $12.5 \%(\mathrm{~N}=2)$ & \\
\hline & 3 & $5.6 \%(\mathrm{~N}=1)$ & $6.2 \%(\mathrm{~N}=1)$ & \\
\hline \multirow[t]{2}{*}{ ER } & positive & $33.3 \%(\mathrm{~N}=6)$ & $87.5 \%(\mathrm{~N}=14)$ & \multirow[t]{2}{*}{0.0019} \\
\hline & negative & $66.7 \%(\mathrm{~N}=12)$ & $12.5 \%(\mathrm{~N}=2)$ & \\
\hline \multirow[t]{2}{*}{ PR } & positive & $27.8 \%(\mathrm{~N}=5)$ & $62.5 \%(\mathrm{~N}=10)$ & \multirow[t]{2}{*}{0.0824} \\
\hline & negative & $72.2 \%(\mathrm{~N}=13)$ & $37.5 \%(\mathrm{~N}=6)$ & \\
\hline
\end{tabular}

Figure 1. Relationship between achieving a pathologic complete response, the ER status and patient age. 


\section{Proportion of $\mathrm{PCR}$ by age and ER status}

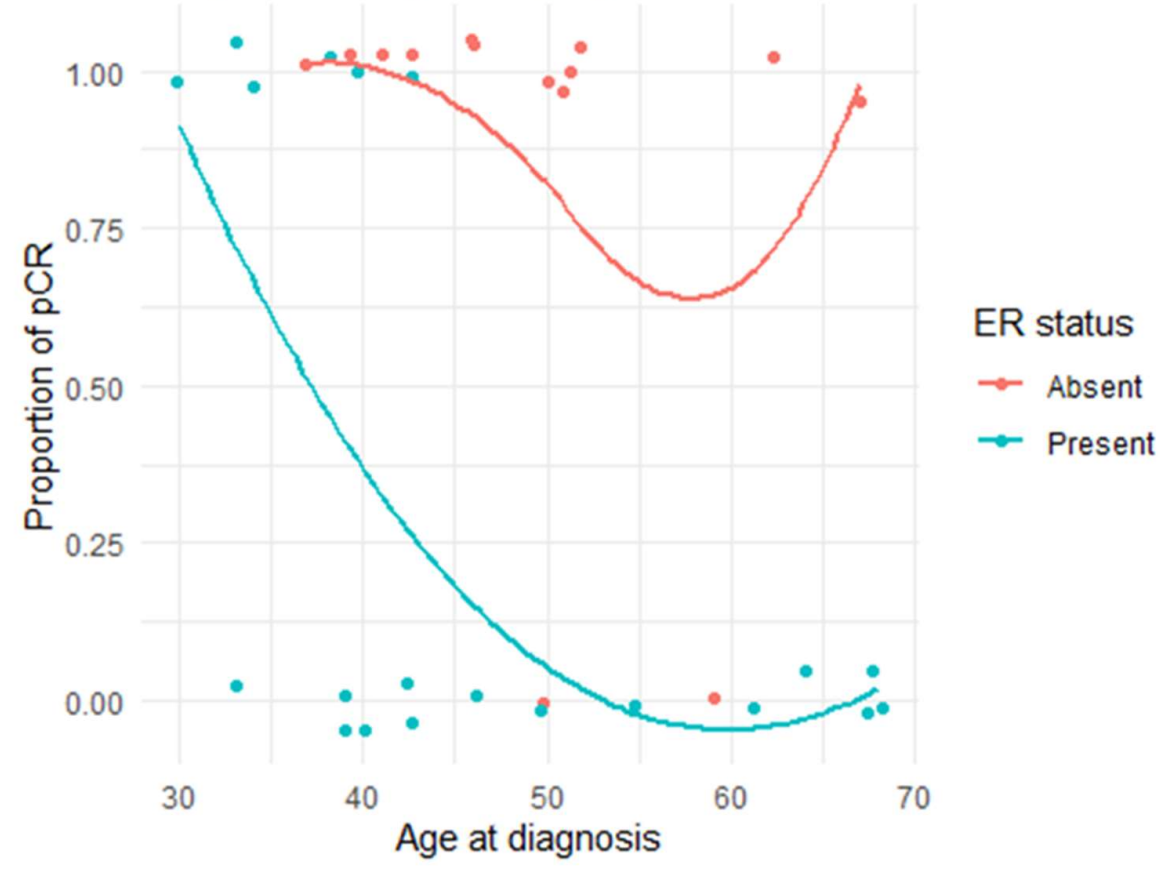

